\title{
Rapid Riverine Flood Mapping with Different Water Indices Using Flood Instances Landsat-8 Images
}

\author{
Asif Sajjad, Jianzhong Lu *, Xiaoling Chen and Nayyer Saleem \\ State Key Laboratory of Information Engineering in Surveying, Mapping and Remote Sensing, Wuhan \\ University, Wuhan 430079, China; asifsajjad@whu.edu.cn (A.S.); xiaoling_chen@whu.edu.cn (X.C.); \\ saleemnayyer@whu.edu.cn (N.S.) \\ * Correspondence: lujzhong@whu.edu.cn; Tel.: +86-27-6877-8755; Fax: +86-27-6877-8229
}

\begin{abstract}
In riverine flood-plain areas, the extraction of the spatial pattern of flood extents and durations during flood instances permit flood planners to anticipate likely threats from floods and to articulate actions to mitigate these events. Rapid flood mapping is a critical aspect for flood estimation and evaluation in the early stage. Accurate early updates of flood inundation have been made possible by remote sensing. The present study applies satellite derived Water indices and Classification method to analyzes and estimates spatio-temporal flood-2014 extent using landsat- 8 flood instance images in Lower Chenab Plain, Pakistan. The lower Chenab plain is particularly prone to frequent riverine flooding but is understudied. It has experienced history worst flooding in 2014. Cloud-free Landsat-8 data was acquired for pre-flood, during-flood, and post-flood periods for detailed analysis. We used Normalized Difference Water Index (NDWI), Modified Normalized Difference Water Index (MNDWI), and Water Ratio Index (WRI) for the delineation of inundated areas. we also used supervised classification to detect and compare flooded areas with used indices. The analysis allowed us to compute flooded areas, duration and flood recession.The proposed RS technique provides an empirical basis for rapid identification of inundated areas, which enable emergency response and relief efforts on newly flooded areas. Thus, our study provides another perspective and substantial contributions to flood monitoring using free satellite data in Pakistan.
\end{abstract}

Keywords: Rapid Flood Mapping; Flooded area Extraction;Water Indices;Landsat image; Remote Sensing; Flood Monitoring

\section{Introduction}

Riverine Flood events are occuring frequently with destructive nature in the world [1,2]. These catastrophic events cannot be totally prevented, but the impacts can be minimized by using effective rapid flood risk reduction strategies with the integration of remote sensing (RS). RS provides timely crucial information on flood impacted areas which is useful for rapid flood mapping [3,4]. Rapid flood mapping is used in many studies for identifying the flooded areas and providing reliable information to emergency flood response organisation [5,6].Many floods that extend over several days, and the spatial extent of flooded area also changes throughout event. The flood Emergency response organization require up-to-date information for monitoring changes throughout event for early response and recovery actions. For that, Multi-temporal Landsat satellite provides up-to-date images, that are essential for the detection of flooded areas in different time [8,9]. The presence of cloud limits the availiability of during flooding time images which ultimately effect the flood mapping. Under these circumstances, RADAR and SAR images are used for mapping that can penetrate clouds and obtain images $[10,11]$. In our case, flood inundated areas are cloud free, since the causative rainfall event occurred in upper part of Chenab river. This event triggered the high flood peak that occurred about 10 days prior to the massive flooding in lower Chenab plain. Certainly, When the study area is cloud-free or the existence of clouds over the affected area is not a problem, multi-spectral landsat data can be used for producing rapid flood maps. RADAR 
data might not be required for rapid flood mapping. Rapid flood mapping based on water indices rely on band ratios resulting from spectral satellite data and apply threshold values to the ratios for the extraction of water areas $[12,13]$. Thus, the present study uses remote sensing derived following water indices Normalized Difference Water Index (NDWI), Modified NDWI and Water Ratio Index (WRI) to delineate flood inundation and evaluate flood duration in order to propose emergency flood response and recovery activities in Pakistan.

\subsection{Study Area}

The lower Chenab plain is selected for this study. It is located between $70^{\circ} 41^{\prime} 13.2^{\prime \prime} \mathrm{E}$ and $29^{\circ} 6^{\prime} 0^{\prime \prime} \mathrm{N}$, and $71^{\circ} 37^{\prime} 58.8^{\prime \prime} \mathrm{E}$ and $30^{\circ} 31^{\prime} 33.6^{\prime \prime} \mathrm{N}$, within the lower part of river Chenab (Figure 1). It is one of the fertile flood prone plains of Pakistan, where riverine floods happen in every year. The Chenab river strated from Himachal Pradesh state, india and it flows through Disputed terrirtory Kashmir and enters at Marala station into Pakistan. we have selected about $120 \mathrm{~km}$ long as our targeted study area along the Chenab River (Figure 1). We then created a 6-km-wide buffer zone around the river as the final extent of our study area.

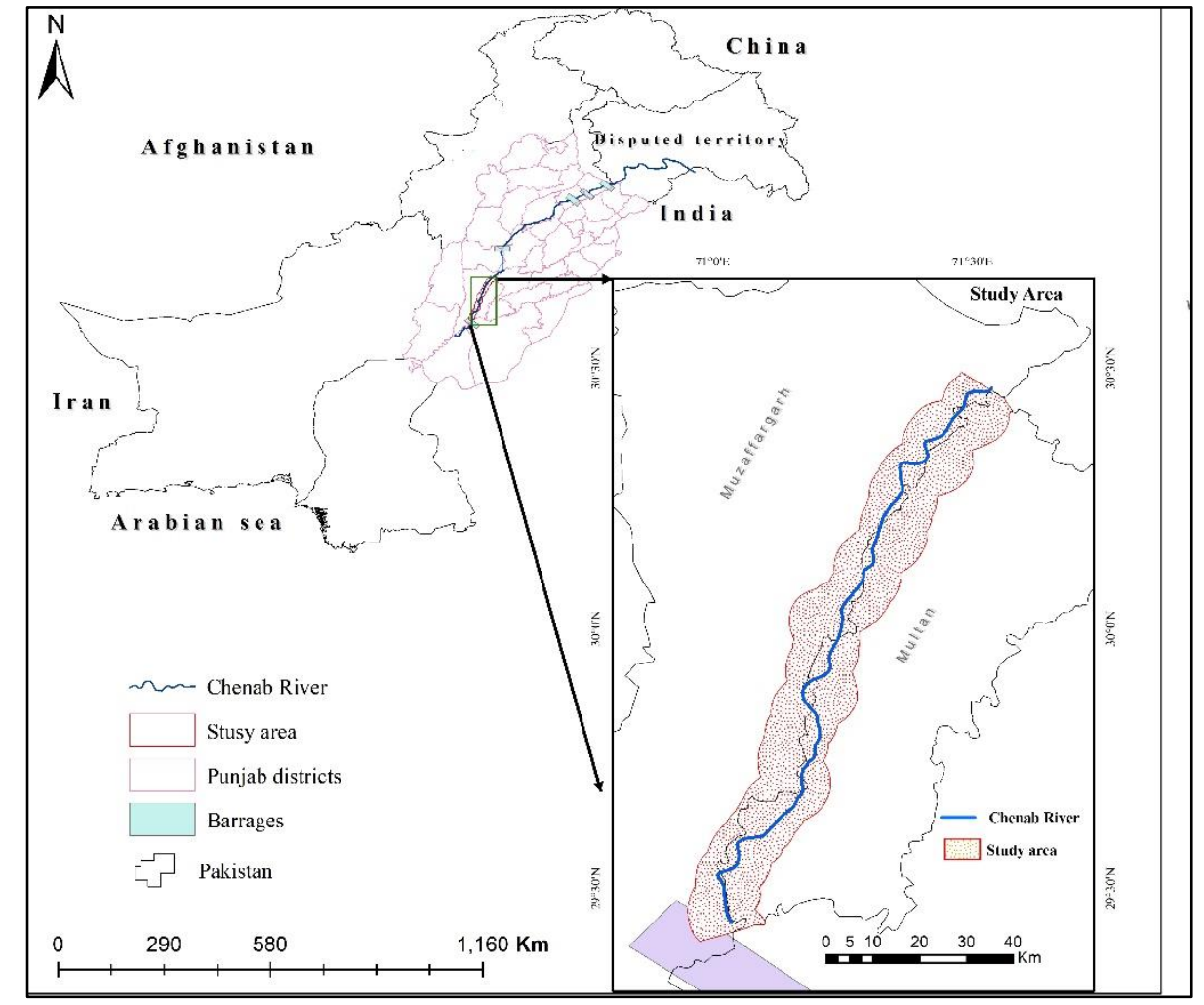

Figure 1. location of the lower Chenab plain, and the zoomed area represents the the extent of our study area along river Chenab system.

\section{Materials and Methods}

The Landsat 8 images were acquired from the United States Geological Survey (USGS) database. Landsat satellite provides free up-to-date data with having a single temporal resolution of $\sim 16$ days, across the world since 1972 [14-16]. In our case, the study area lies on two Adjacent landsat satellite Paths ( 150 and 151), that provides a unique opportunity to acquire images with a high temporal resolution of $\sim 8$ days, which allows us to carried out rapid flood mapping and monitoring in lower chenab. We used 8 temporal landsat images obtained between $17^{\text {th }}$ September and 27 November 2014. We also used Google Earth (GE) and GPS data to collect validation points, which were used to validate flood mapping result. 
We have used different water indices including NDWI,MNDWI and WRI for the detection of flood inunadation from Landsat datas in lower chenab during flood -2014 using Arc GIS 10.5. NDWI index is presented by McFeeters [14], is very efficient for flood water detection, as It has robust water absorption and reflection of vegetation in Near infra-red (NIR) bands and high reflection in Green band. The NDWI is calculated using green and NIR bands, as given by Equation (1):

$$
N D W I=\frac{\text { Green }-\mathrm{NIR}}{\text { Green }+ \text { NIR }}
$$

Result suggested that this index has strong ability to distinct water and vegetation cover, but it has some difficulties in case built up environment exist in water areas. In order to overcome this limitation, $\mathrm{Xu}$ [15], proposed MNDWI index, which works efficiently to differentiate water from built up area. The index is determined using green and shortwave infrared (SWIR) bands, as given by Equation (2):

$$
M N D W I=\frac{\text { Green }- \text { SWIR }}{\text { Green }+ \text { SWIR }}
$$

WRI is another index as presented by Shenand $\mathrm{Li}$ [16], is the proportion between the total of the spectral reflectance in the Green and RED bands to the NIR and SWIR bands. The ratio is calculated as shown in Equation (3):

$$
W R I=\frac{\text { Green }+ \text { RED }}{\text { NIR }+ \text { SWIR }}
$$

Furthermore, we have given Threshold value manually for land-water classes for each index to categories the image into two classes, water and non-water. Accurate threshold value has been defined by performing comparison to reference map made using visual interpretation. Near infrared (NIR) band is normally chosen for visual interpretation of water areas due to its strongly absorption by water and reflection by vegetation and bare soil. The validation of rapid flood maps were evaluated using GPS and GE points. ArcGIS based Spatial overlay analysis was used to overlaid points on flood extent images. Further, the values of these points were assessed and calculated for accuracy assessment.The accuracy results were presented in confusion matrix. Overall, producer, and user accuracies were calculated of resulted flood extent images.

\section{Results}

\subsection{Rapid Flood Mapping using Indices}

The temporal flood-2014 inundaated areas were delineated to calculated the most affected areas in lower chenab plain. Figure 2a,b,c shows the flood inundation with a cumulative flood peak on 17 September, which almost remained stable until the 24 September, and then the flood inundation regularly reduced till 27 November. Rapid flood inundation derived from MNDWI index revealed the inundated area with high overall accuracy as shown in Table.1a. The MNDWI index shows the peak-flood extent of 17 September image that covers an area of $1023.4 \mathrm{~km}^{2}$ (Figure 2a), while NDWI index revealed the total of $1035 \mathrm{~km}^{2}$ area was inundated (Figure $2 \mathrm{~b}$ ) and WRI showed the peak flood inundation covered an area of $860 \mathrm{~km}^{2}$ (Figure 2c). Further the detail of flood inundation is given in Figures $2 a, b, c$ and 3 . The overall result showed that northern and southwestern parts were the most inundated and affected in lower chenab. The inundated area further reduced in three stages: In the first stage the southern part was reduced from $17^{\text {th }}$ September to $10^{\text {th }}$ October. In the second phase, midde portion started to decrease from $10^{\text {th }}$ to $26^{\text {th }}$ October, and in the final phase, all the inundated area water retreated until 27 November 2014. 


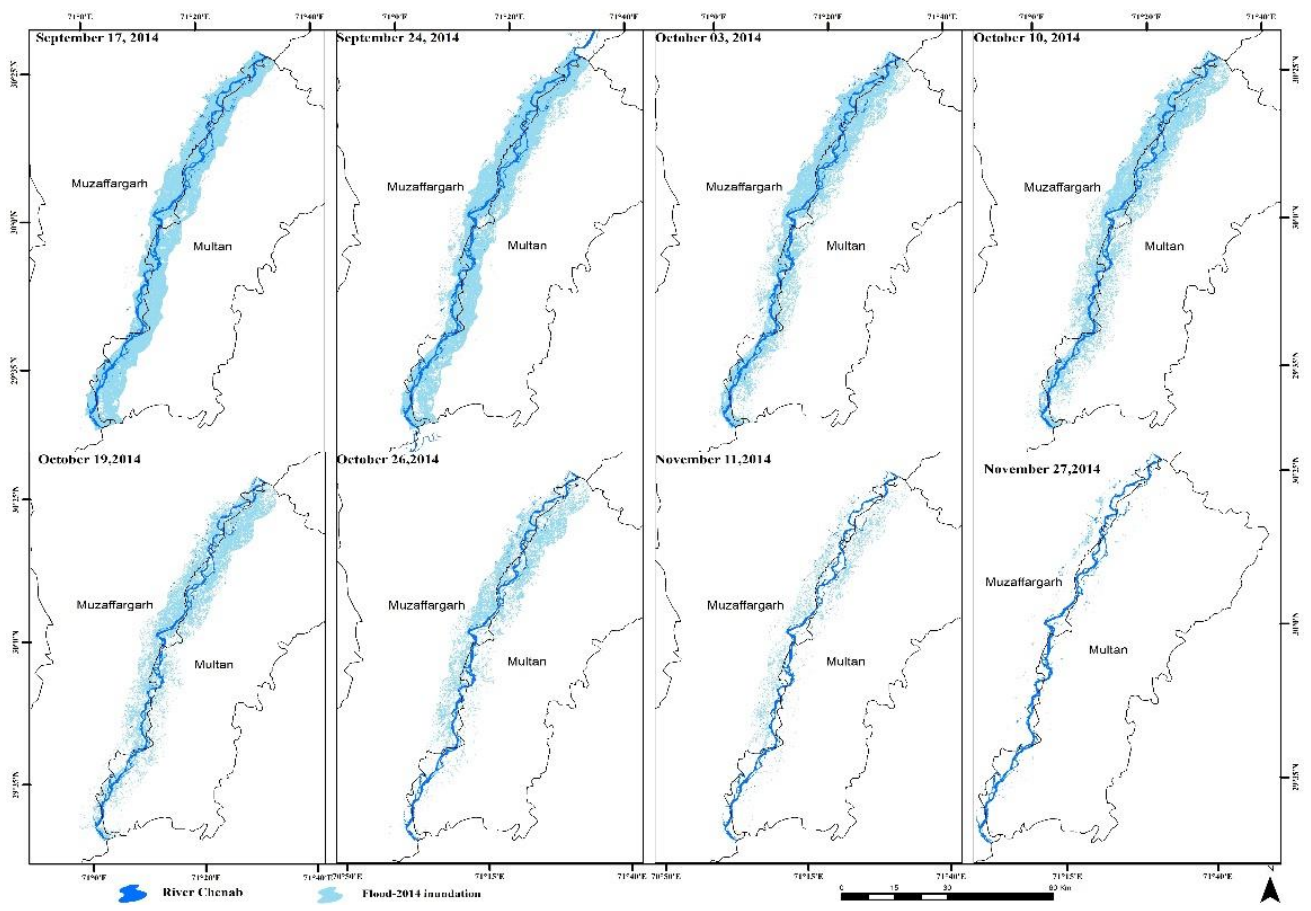

Figure 2a. Multi-temporal flood inundation extent, peak flood extent, based on MNDWI index.

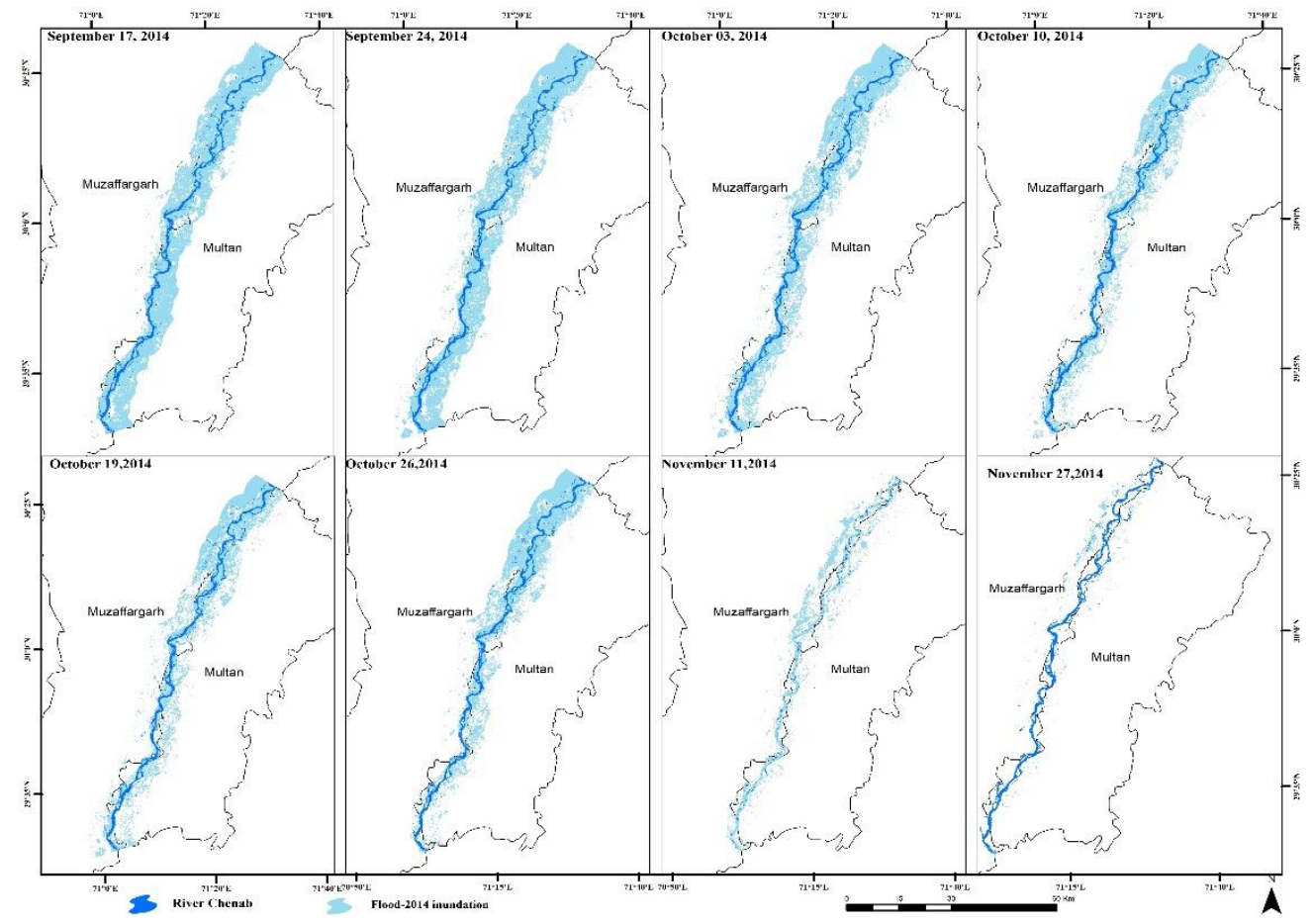

Figure 2b. Multi-temporal flood inundation, peak flood extent, based on NDWI index. 


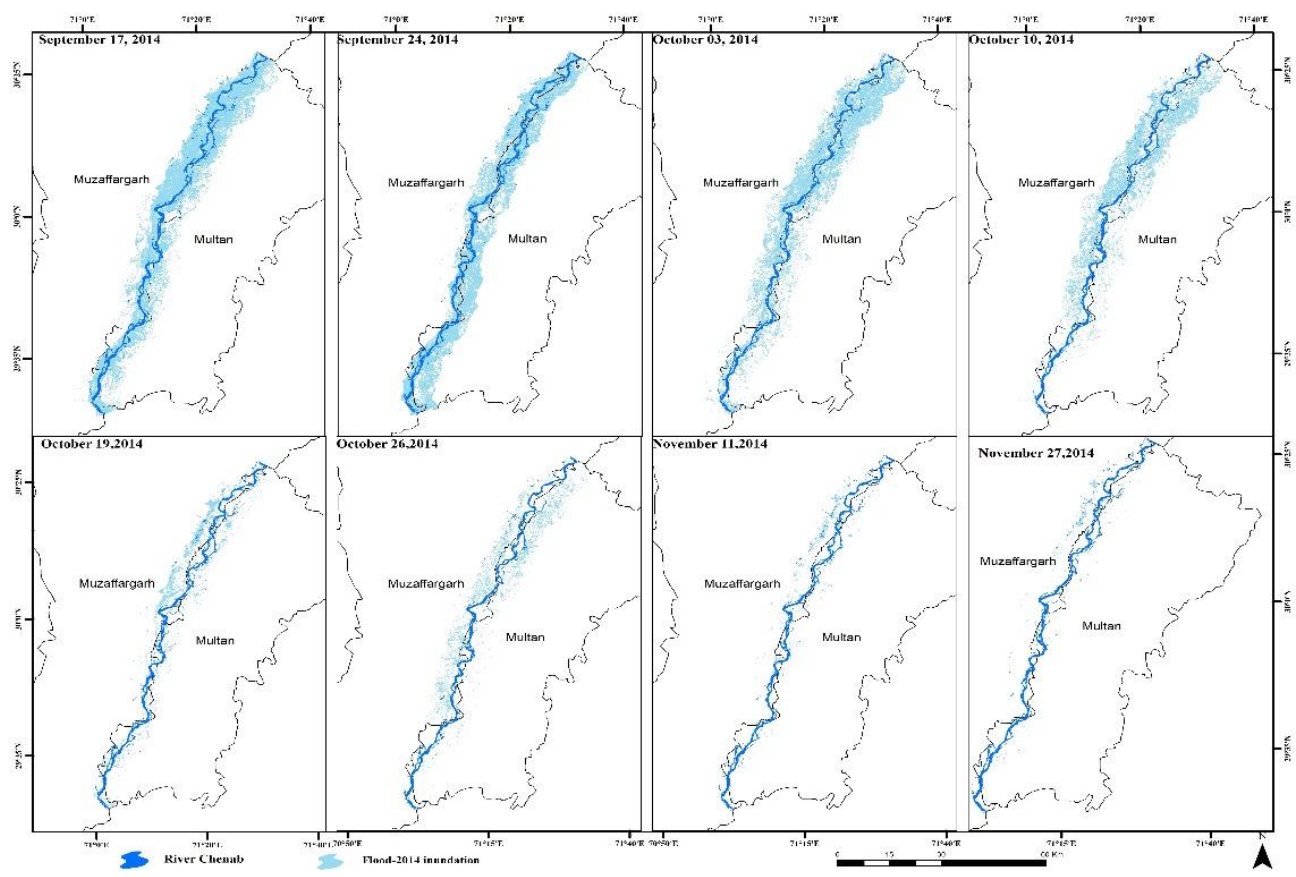

Figure 2c. Multi-temporal flood inundation, peak flood extent, based on WRI index.

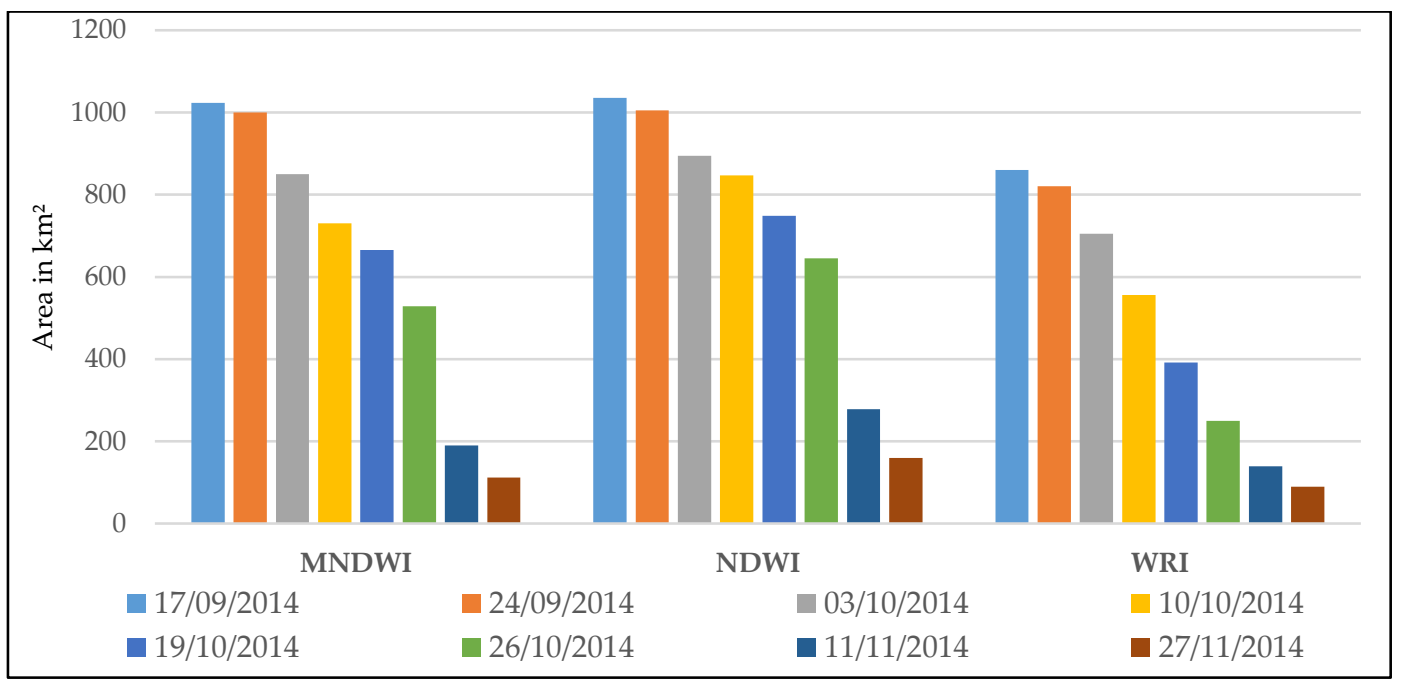

Figure 3. Flood Inundated areas acquired through mentioned water indices on different dates in lower chenab.

\subsection{Accuracy Assesment}

The overall accuracy of mentioned indices are obtained from all images is shown in Table 1 . The accuracy result revealed that the MNDWI index derived inundation obtained the highest overall accuracy of $93 \%$, from $17^{\text {th }}$ September and $92 \%$ from $24^{\text {th }}$ September images, while the highest achieved overall accuracy of NDWI index is $89 \%$, from $24^{\text {th }}$ September. The highest attained overall accuracy of WRI index is $85 \%$, from $11^{\text {th }}$ November. The detail about overall accuracy is listed in Table.1. 
Table 1. overall accuracy assessment of mentioned indices of flood-2014 inundation.

\begin{tabular}{cccc}
\hline Landsat-8 images & MNDWI index & NDWI index & WRI index \\
\hline $\mathbf{1 7 / 0 9 / 2 0 1 4}$ & 0.93 & 0,87 & 0.81 \\
$\mathbf{2 4 / 0 9 / 2 0 1 4}$ & 0.92 & 0.89 & 0.79 \\
$\mathbf{0 3 / 1 0 / 2 0 1 4}$ & 0,91 & 0,85 & 0.84 \\
$\mathbf{1 0 / 1 0 / 2 0 1 4}$ & 0,89 & 0,82 & 0.82 \\
$\mathbf{1 9 / 1 0 / 2 0 1 4}$ & 0.90 & 0,81 & 0.83 \\
$\mathbf{2 6 / 1 0 / 2 0 1 4}$ & 0.91 & 0,79 & 0.81 \\
$\mathbf{1 1 / 1 1 / 2 0 1 4}$ & 0.91 & 0,85 & 0.85 \\
$\mathbf{2 7 / 1 1 / 2 0 1 4}$ & 0.91 & 0,85 & 0.81 \\
\hline
\end{tabular}

\section{Discussion}

Our study reveals that optical landsat data permits the detailed analysis of flood inundation. In our case, Landsat- 8 images $(\sim 30 \mathrm{~m})$ are used for rapid flood inundations mapping, because of the absence of any free SAR images $[4,17,18]$. Firstly, It is evident that Landsat data have limitation to the point of not being able to acquire data in a timely manner, which reduces their suitability for flood inundation and impact assessment [8,9]. However, our study area lies in two adjacent Landsat satellite paths (150 and 151), which enable us to obtain high temporal resolution ( 7 days) data , versus a single 15-day temporal resolution for an area [19]. As such, the high temporal resolution allowed us for a detailed flood inundation mapping. Secondly, cloud weather condition can also restrain the ability to acquire during flood Landsat images. In comparison, SAR and RADAR satellites can easily obtain images in all weather conditions[20-22]. In our case, study area was completely cloud-free, as the causative weather events occurred in upper Chenab (Fig. 2) about 10 days before the flood reached the study area.In this study, we also carried out a field observation based survey in order to observe the real time flood situation. Finally, the accuracy $f$ mentioned indices were considered in order to show the results reliability. The MNDWI index had achieved an average highest overall accuracy of $90 \%$, while the NDWI and WRI images produce an average overall accuracy of about $85 \%$ and $82 \%$ respectively (Table 1 ). In this study, the MNDWI index produced an excellent result.The NDWI index result shows, in some regions, wet sand and bare soil was mixed with water body. This is also observed in some occasions, where built-up area was also confused with water area. The WRI index result shows that the shallow water areas was not detected and as a result the water area was smaller in all images in compare with other used indexes.

The peak-flood observed on 17 $7^{\text {th }}$ September, 2014, and then the water remained for almost two months, as shown in Figures 2a,b and c. The flooded water receded in three stages; in peak stage, water slightly receded at a rate of about $11 \mathrm{~km}^{2} /$ day, until $10^{\text {th }}$ October. In moderate stage the flood water significantly reduced at a rate of $18 \mathrm{~km}^{2} /$ day until 26 October. In the normal stage, flood water decreases with a rate of $11.5 \mathrm{~km}^{2} /$ day until $27^{\text {th }}$ November and river regained its pre-flood normal flow.

\section{Conclusions}

Flood Inundation maps derived from used indices can be used for rapid flood mapping. Through these technique and satellite images, the flooded areas can be delineated with no time. The combination of indices have contributed to reliable flood extent mapping using Landsat data. However, in most cases, these indices are used separately to produce flood mapping. Furthermore, I the exploitation of two Landsat adjacent paths provides a high temporal resolution, which can be used for effective rapid flood assessment. This exploitation of two paths increased the temporal resolution, from 15days to 7 days, which can have made it possible flood mapping for emergency response and early relief operations. Thus, this research provides another avenue to flood mapping and impact assessment using free satellite data

\section{Author Contributions:}


Funding:

\section{Acknowledgments:}

Conflicts of Interest: The authors declare no conflict of interest

\section{References}

1. Syvitski, J.P.; Brakenridge, G.R. Causation and avoidance of catastrophic flooding along the Indus River, Pakistan. GSA Today. 2013, 23, 4-10.

2. Bhatt, C.M.; Rao, G.S.; Farooq, M.; Manjusree, P.; Shukla, A.; Sharma, S.V.S.P./ Kulkarni, S.S.; Begum, A.; Bhanumurthy, V.; Diwakar, P.G.; Dadhwal,VK. Satellite-based assessment of the catastrophic Jhelum floods of September 2014, Jammu \& Kashmir, India. Geomatics, Nat. Hazards Risk. 2016, 8, 309-327.

3. Zhang, P.; Lu, J.; Feng, L.; Chen, X.; Zhang, L.; Xiao, X.; Liu, H. Hydrodynamic and Inundation Modeling of China's Largest Freshwater Lake Aided by Remote Sensing Data. Remote Sens. 2015, 7, 4858-4879.

4. Khalid, B.; Cholaw, B.; Alvim, D.S.; Javeed, S.; Khan, J.A.; Javed, M.A.; Khan, A.H. Riverine flood assessment in Jhang district in connection with ENSO and summer monsoon rainfall over Upper Indus Basin for 2010. Nat. Hazards. 2018, 92, 971-993.

5. Haq, M.; Akhtar, M.; Muhammad, S.; Paras, S.; Rahmatullah, J. Techniques of Remote Sensing and GIS for flood monitoring and damage assessment: A case study of Sindh province, Pakistan. Egypt J Rem Sens Space Sci. 2012, 15, 135-141

6. Mahmood, S.; Rahman, A.; Sajjad, A. Assessment of 2010 flood disaster causes and damages in district Muzaffargarh, Central Indus Basin, Pakistan. Environ. Earth Sci. 2019, 78, 63.

7. Sajjad, A.; Lu, J.; Chen, X.; Chisenga, C.; Mahmood, S. The riverine flood catastrophe in August 2010 in South Punjab, Pakistan: Potential causes, extent and damage assessment. Appl. Ecol. Environ. Res. 2019, 17, 14121-14142

8. Munasinghe, D.; Cohen, S.; Huang, Y.F.; Tsang, Y.P.; Zhang, J.;, Fang, Z.F. Intercomparison of Satellite Remote Sensing-Based Flood Inundation Mapping Techniques. J. Am. Water Resour. Assoc. 2018, 54, 834846.

9. Alphan, H., Doygun, H., Unlukaplan, Y.I. Post-classification comparison of land cover using multitemporal Landsat and ASTER imagery: The case of Kahramanmaras, Turkey. Environ Monit Assess. 2009, 151, 327336.

10. Rokni, K.; Ahmad, A.; Selamat, A.; Hazini, S. Water feature extraction and change detection using multitemporal Landsat imagery. Remote Sens. 2014, 6, 4173-4189.

11. AlFaisal, A.; Kafy, A.A.; Roy, S. (Integration of Remote Sensing and GIS Techniques for Flood Monitoring and Damage Assessment: A Case Study of Naogaon District, Bangladesh. J Remote Sens. GIS 2018, 7, 236.

12. Joyce, K.E.; Belliss, S.E.; Samsonov, S.V.; McNeill, S.J.; Glassey, P.J. A review of the status of satellite remote sensing and image processing techniques for mapping natural hazards and disasters. Prog. Phys. Geogr. 2009, 33, 183-207.

13. Revilla-Romero, B.; Hirpa, F.A.; Pozo, J.T.; Salamon, P.; Brakenridge, R.; Pappenberger, F.; De Groeve, T. On the use of global flood forecasts and satellite-derived inundation maps for flood monitoring in datasparse regions. Remote Sens. 2015, 7, 15702-15728.

14. McFeeters, S.K. The use of the normalized difference water index (NDWI) in the delineation of open water features. Int. J. Remote Sens. 1996, 17, 1425-1432.

15. $\mathrm{Xu}, \mathrm{H}$. Modification of normalized difference water index (NDWI) to enhance open water features in remotely sensed imagery. Int. J. Remote Sens. 2006, 27, 3025-3033.

16. Shen,1.; Li, C. Water body extraction from Landsat ETM+ imagery using adaboost algorithm. IEEE. 2010 18th International Conference on Geoinformatics; Beijing. 2010. 18-20, 1-4.

17. Chohan, K.; Ahmad, S.R.; Islam, Z.; Adrees, M. Riverine flood damage assessment of cultivated lands along Chenab River using GIS and remotely sensed data: A case study of district Hafizabad, Punjab, Pakistan. J Geogr. Inf. Syst. 2015, 7, 506-526

18. Sajjad, A.; Lu, J.; Chen, X.; Chisenga, C.; Saleem, N.; Hassan, H. Operational Monitoring and Damage Assessment of Riverine Flood-2014 in the Lower Chenab Plain, Punjab, Pakistan, Using Remote Sensing and GIS Techniques. Remote Sens. 2020, 12, 714.

19. Notti, D.; Giordan, D.; Caló, F.; Pepe, A.; Zucca, F.; Pedro Galve, J. Potential and Limitations of Open Satellite Data for Flood Mapping. Remote Sens. 2018, 10, 1-30. 
20. Uddin, k.; Matin, M.A.; Meyer, F.J. Operational Flood Mapping Using Multi-Temporal Sentinel-1 SAR Images: A Case Study from Bangladesh. Remote Sens. 2019, 11, 1581.

21. Pradhan, B.; Pirasteh, S.; Shafie, M. Maximum flood prone area mapping using RADARSAT images and GIS: Kelantan river basin. Int. J. Geoinformatics 2009, 5, 11-23.

22. Giordan, D.; Notti, D.; Villa, A.; Zucca, F.; Calò, F.; Pepe, A.; Dutto, F.; Pari, P.; Baldo, M.; Allasia, P. Low cost, multiscale and multi-sensor application for flooded area mapping. Nat. Hazards Earth Syst. Sci. 2018, $18,1493-1516$

(C) (1)

(C) 2020 by the authors. Submitted for possible open access publication under the terms and conditions of the Creative Commons Attribution (CC BY) license (http://creativecommons.org/licenses/by/4.0/). 